\title{
The Internet of Things Readiness in Public Organization: Descriptive Analysis
}

\author{
Norjanah Sulaiman ${ }^{1}$, Nurazean Maarop ${ }^{2 *}$, Ganthan Narayana Samy ${ }^{3}$, Norshaliza Kamaruddin ${ }^{4}$, \\ Pritheega Magalingam ${ }^{5}$, Doris Wong Hooi Ten ${ }^{6}$ \\ ${ }^{1,2,3,4,5,6}$ Faculty of Technology and Informatics Razak, Universiti Teknologi Malaysia \\ 2*nurazean.k1@utm.my
}

Article History: Received: 10 November 2020; Revised: 12 January 2021; Accepted: 27 January 2021; Published online: 05 April 2021

\begin{abstract}
The Internet of Things (IoT) is a system of interrelated computing devices. IoT involves mechanical and digital machines, objects, animals or people that are indicated with unique identifiers and the ability to transfer data over a network without requiring human-to-human as well as human-to-computer interaction. Government of Malaysia in 2015 has introduced the National Internet of Things Strategic Road Map as a way to provide the backbone of modern and smart cities as well to sustain the economic growth. However, the factors influencing IoT readiness in Malaysian organization needs to be further investigated. The purpose of this study is to investigate, identify and propose the readiness factors of IoT implementation. A survey involving a distribution of questionnaire to 30 respondents to get a descriptive indication coupled with interviews with 5 key expert employees from relevant agencies were executed. As a result, there are five factors being proposed and validated descriptively to influence the readiness of implementing IoT in Malaysia. These factors are Human Perspective, Technology Perspective, Governance and Management Perspective, Security Perspective and Policy and Law Perspective. For future work, this study suggest to include more participants using power statistics, hypothetical model testing and expand the questionnaire to other organization in order to develop a more comprehensive result of IoT readiness in Malaysia.

Keywords: Technology Readiness, Internet of Things, Public Organization
\end{abstract}

\section{Introduction}

The Internet of Things (IoT) currently receiving much research attention and effort from the academia as well as the industry player to provide the backbone of modern and smart societies (Eiza et al, 2015). Therefore, most of the organizations together with government sectors hunger for leverage the latest IoT solutions so that they can harness the IoT capabilities and extend their reach well beyond their traditional parameters like usual perception amongst citizens. IoT technology has had a profound impact to our lives such as interactions with others to the tasks we perform and the way we entertain ourselves.

The IoT refers to a collective of Internet-connected consumer devices, manufacturing systems, business tools, customer service appliances, medical equipment, agricultural sensors, and other things (Pujar and Satyanarayanab, 2015). Hence, IoT is a system of interrelated computing devices, mechanical and digital machines, objects, animals or people that are provided with unique identifiers and the ability to transfer data over a network without requiring human-to-human or human-to-computer interaction. As IoT continues to evolve, communication is not only dialogue between people, yet the information is gathered and shared between people, devices as well as machine-to-machine. IoT allows to create a digital shadow of everyday processes and everyday items that are being used in our daily life as all the devices are connected and present around us in a variant types object such as putting sensors along with actuator, a radio-frequency identification (RFID) tags, mobile phones etc. (Xianping Wang et al, 2018). Despite of all that technology to support the blooming of IoT, it is still considered as very early stages as everyone is verge trying to envision the roadmap to persuade the stakeholders with respect their needs (Asir, 2016). The growth forecast of IoT is very high as it uses a set of technologies to connect to objects. Besides this new paradigm is bound to impact new business models along with consumer experience and everyday life (Pujar and Satyanarayanab, 2015). Moreover, this evolve of technology in IoT will brings new opportunities, threats and solutions, with that it can trigger the organization as well as the stakeholder to be ready to adopt it (Saarikko et al, 2017). Based on that, the technology as well as security can be appropriate factors towards IoT readiness in Malaysian public organisation. Increasing number of mobile users nowadays represent Internet users with mobile device penetration in Malaysia beyond 150 percent. According to Badarudin et al, (2019) this number will be increasing up to 280 percent in 2025. This factor encourages effort towards IoT readiness in public agencies and this require intensive study about human issues such as attitude, usage and expectations in the application of smart city areas including smart lighting, smart home, smart roads, smart phone detection and smart parking (Asir, 2016). Hence, with the advancement of digital era have accentuated the use of smart devices has surpassed the number of populations in which Internet requirements are no longer an option but a necessity. As reported in Invest KL Malaysia (Burgess et al, 2018), 
the extensive of this growth of connected devices in Malaysia, is expected to generate over 14,000 new jobs and contribute billions of ringgits to the economy. This factor can have led technology opportunities that originated by IoT with predicted for: 1) Application and services amounting to RM34 billion in 2025 compared to RM7.5 billion for 2020; and 2) Produces of the devices at RM1.0 billion an RM4.3 billion for years 2020 and 2015 respectively (MIMOS, 2015).

Due to significance of IoT, the government of Malaysia has introduced the National IoT Strategic Roadmap in 2014 as a way to sustain the economic growth (Zaidi and Faizal, 2017). The importance of IoT that will be reframing and widespread driver of change and enhancement by potential append new dimensions to the industry in Malaysia. The potential new dimensions to the industry are in following ways (MIMOS, 2015): 1) Testing facilities for interoperability, standards compliance and export-related testing; 2) Development of standardization software to address standard silos in order to facilitate the creation of niche application and services; 3) System integration services in order to create some specialists from speculators through interaction with various contributors in the ecosystem. In regard to IoT in public service, Dachyar et al. (2019) found that these include intelligent transportation system, smart campus, smart school, general education, city, traffic management, transportation system and water. According to analysis based on Google, The major challenges for the government are to understanding citizens' changing needs, as well as the obstacles they face in attaining those services (MAMPU, 2017). Therefore, it is a major concern to investigate the readiness amongst public agencies to adapt and understand of IoT along with the issues or challenges that might exist during implementation

\section{Literature Review}

National IoT Strategic Roadmap reported the strengths and weaknesses of IoT Implementation based on Technology, Resource, Societal and Political factors (MIMOS, 2015). Among the key challenges include security and privacy concerns, adoption and adaptation fear, broken linkages across industries and multiple agencies working in silos.

In this study in order for us to identify the IoT readiness factors, we have reviewed the related concepts from various readiness models that have been studied by previous researches according to areas in ICT domain. Hence, reviews of such as adoption of cloud computing, cultural e-government readiness model, organizational readiness model for digital innovation and Green readiness model were performed to better understand the theoretical background of technology readiness. This effort is supported by Elazhary et al. (2019) who claimed that there is an intersection of main research area between cloud computing, mobile computing and IoT.

Kauffman et al. (2018) propose categories and measures to evaluate the readiness of adoption cloud computing and assess the required adjustments in strategy and management, technology and operations, and business policy. Four relevant categories were identified in this readiness model, which is: 1) technological; 2) organizational; 3) economic; and 4) environmental. Moreover, they also identified the sub-category for each of category and proposed a metrics suite consists of 21 measures to identified the readiness of firm level to adopt a cloud computing. Indeed, when evaluating the technology related to industry 4.0, it is important to develop a readiness model considering respective standard and structure to support managers for identifying the strategic action in improving readiness level (Lucato 2019) and (Hussain 2020). In the other study done by Lokuge et al (2018), multidimensional constructs to measure organizational readiness for digital innovation with sample of 189 firms were used. They proposed a construct under seven (7) categories with 21 measures, to identify the readiness of organization to implement the digital innovation since the rise and growth the products that strongly attribute to the advancements in modern technology. In regard to the industry 4.0, presence of a digital infrastructure coupled with the analytical capabilities in dealing with big data appear as dimensional indicators to readiness for Industry 4.0 (Castelo-Branco et al., 2019). A study accessing consumer readiness for participation in IoT based demand response business model yielded the importance of individual factors such as attitude as well as security perspective such as trust in organization (Radenković et al 2020).

\section{Methodology}

We employed a mixed methodology triangulation approach comprising quantitative and quantitative data collection and analysis techniques to describe the findings of this research work. As the aim of this project is to explore the IoT readiness descriptively among several government agencies in Putrajaya, we only used small samples size to fulfill our research query. Questionnaire survey was conducted and the questionnaire were distributed to the respective respondents using online survey tool. As a result, only 30 participants agreed to participate in the quantitative survey. On the other hand, 5 technology experts were interviewed to get their 
intense opinion regarding the factors influencing IoT readiness in public sector. They were selected purposively to help describe the readiness qualitatively. The selection of participants were done based on their experience in areas such as integrated systems thus are related and responsible with RFID and business intelligence, Information Communication Technology consultation, Information Technology (IT) operation, Block Chain technology, digital content as well as IT officer who adequately had experienced working with project management and system monitoring system.

\section{Results and Discussion}

Based on literature review, we deduced five factors based on frequency and significance in other related studies. These include: 1) Human factors [(Badarudin et al, 2019), (Katan et al, 2018), (Beck et al, 2018), (Hussain et al. 2017), (Asir, 2016)]; 2) Technology [(Kauffman et al, 2018), (Katan et al, 2018), (Asir, 2016), (Xiwei Wang et al, 2018)]; 3) Security [(Xiwei Wang et al, 2018), (Asir, 2016); 4) Policy and Law [(Katan et al, 2018), (Beck et al, 2018, (Zaidi and Faizal, 2017)]; and 5) Governance and Management [(Katan et al, 2018), (MIMOS, 2015)].

\subsection{Demographic Information}

Most of respondent are female with 66.7 percent or 20 female participants out of total 30 participants for item gender. As for item experience area, the respondent is allowed to choose more than one area that related with their working experience or study. Most of respondent are experience in network area and other IT domain area with 53.3 percent whereas block-chain only contributes 3.3 percent or only 1 respondent have experience in this area. Item education, the respondent has been given six choices namely certificate, diploma, bachelor degree, master degree, $\mathrm{PhD}$ and others. From this item most of participants are bachelor degree holder with percentage 21.1 percent. Whereas for item working experience most of participants have 11 to 15 years working experience in related area of ICT domain. In regard with readiness level, we used scale such as 1- not ready, 2- weakly ready, 3- moderately ready, 4- ready, and 5- strongly ready. The result is as shown in Figure 1. Majority of respondents are agreed that the IoT readiness level is moderately ready to be implemented in Malaysia.

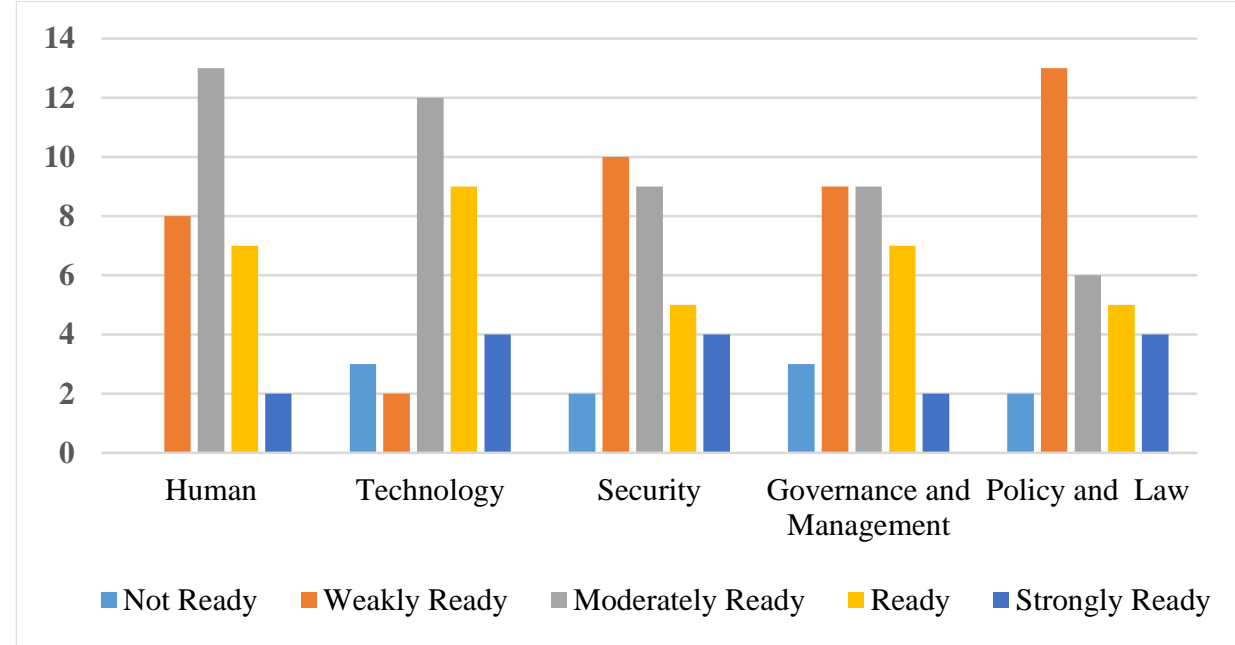

Figure 1. IoT Acceptance Readiness Level by Factors

\subsection{Reliability Test}

The outcome of reliability test using cronbach alpha indicator of all factors is above 0.7 except for Human factor (0.610). Nunnally and Berstein (1993) claimed that any internal consistency reliability value should be above 0.7 in early stages of research, and above 0.8 or 0.9 in more advanced stages of research are considered satisfactory. On the other hand, Henseler et al. (2009) claimed that only with loading value below 0.6 would be considered lack of reliability. Based on reliability readiness analysis yielded in this study, all of five factors deduced from literature review are considered reliable as a readiness factors towards IoT implementation in Malaysia. In particular the results of cronbach alpha for each factor are as follows: Governance and Management: 0.802, Human: 0.610, Policy and Law: 0.901, Security: 0.871, Technology: 0.837 and Success Level: 0.895 


\subsection{Descriptive Analysis}

We enquire the participant to rate the importance of each sub-factors by using 5-likert scale (1- strongly disagree to 5- strongly agree). Descriptively all factors are reported to be significant as majority participants have shown high level of agreement for each factors. This indicates that these factors are important to ensure readiness of IoT implementation. In particular factor namely Security has been viewed as most important indicator towards IoT acceptance among the participants as the median score appeared as strongly agree. Indeed the standard deviation for all factors is below 1.0 indicating high consensus among participants. The findings of descriptive analysis are as shown in Table 1.

Table 1. Descriptive Results (N=30)

\begin{tabular}{|l|l|l|l|l|}
\hline Factor & Sub-Factor Mean & Median & $\begin{array}{l}\text { Standard } \\
\text { Deviation }\end{array}$ \\
\hline Human & Usage, Attitude,Expectation, Expertise & 4.252 & 4 & 0.704 \\
\hline Technology & Infrastructure, Software, Hardware, Interoperability & 4.383 & 4 & 0.649 \\
\hline Security & $\begin{array}{l}\text { Protocol, Security Features, Standardization, Security } \\
\text { Measures }\end{array}$ & 4.425 & 5 & 0.595 \\
\hline $\begin{array}{l}\text { Governance and } \\
\text { Management }\end{array}$ & $\begin{array}{l}\text { Management Support, Financial Aid, Training \& } \\
\text { Awareness }\end{array}$ & 4.346 & 4 & 0.580 \\
\hline Policy and Law & $\begin{array}{l}\text { Enforcement Body, Architecture, Policy and } \\
\text { Regulation }\end{array}$ & 4.425 & 4 & 0.589 \\
\hline
\end{tabular}

\subsection{Qualitative Result}

The interview session was conducted to gather information from IoT expert regarding the issue of concern based on 5 key informants opinion and perception. The excerpts were analyzed based on consensus points across responses. The rating shows that all factors are either important or very important. These decisions are made according to consensus, words strength and also brief scale scoring we asked them to rate. The details finding regarding the factors of IoT readiness is further explained. The summary of interview results is shown in Table 2 .

Table 2. Interview Excerpts

\begin{tabular}{|c|c|c|}
\hline Factor & Rating & Example of Excerpts \\
\hline Human & Important & $\begin{array}{l}\text { "......Human is the really importance roles in ensuring IOT readiness. By knowing } \\
\text { human perspective IOT can be done in correct way. Attitude must be in mood of } \\
\text { following the IoT and not works in denial....." } \\
\text { (Participant } 1 \text { ) } \\
\text { "....its all about attitude. People some time do not aware of the existence of the new } \\
\text { technology that has been installed in front of them. They heard about the technology but } \\
\text { does not eager to understand and adopt..."(Participant } 2 \text { ) }\end{array}$ \\
\hline Technology & $\begin{array}{l}\text { Very } \\
\text { Important }\end{array}$ & $\begin{array}{l}\text { "...Technology readiness is something that really important in our daily life. Kuala } \\
\text { Lumpur for example is really ready with terms such as infrastructure, technical } \\
\text { framework but the remote area is still not ready with technology development. The idea } \\
\text { of IoT can really works if there are development done in remote area also. It is a right } \\
\text { time to start with urban first then slowly to the remote and rural area..."(Participant 5); } \\
\text { ".... technology perspective plays the main part in embarking to a new style of life. } \\
\text { Infrastructure has to be ready first..." (Participant 2) }\end{array}$ \\
\hline Security & $\begin{array}{l}\text { Very } \\
\text { Important }\end{array}$ & $\begin{array}{l}\text { "...security is the key issue and very challenging in IoT implementation. However, the } \\
\text { most important thing is the awareness of the user on the security..." (Participant 4); } \\
\text { "....Absolutely, security is the key factor..." (Participant 5) }\end{array}$ \\
\hline $\begin{array}{l}\text { Governance } \\
\& \\
\text { Management }\end{array}$ & $\begin{array}{l}\text { Very } \\
\text { Important }\end{array}$ & $\begin{array}{l}\text { "....Participation and involvement of management in an organization is very important, } \\
\text { and based on my experience, without the involvement of management of a project is } \\
\text { incapable of being implemented. It's the same in IoT's. Awareness and support from } \\
\text { management can be especially helpful in financial terms for IoT budget applications, as } \\
\text { well as after IoT projects are implemented for enforcement purposes and so on. The } \\
\text { involvement of the management will determine the extent to which a project will be } \\
\text { successfully implemented..." (Participant } 3 \text { ); "......Management especially at the highest } \\
\text { level should take a very crucial part in every single detail to support IoT. Management }\end{array}$ \\
\hline
\end{tabular}




\begin{tabular}{|l|l|l|}
\hline & & $\begin{array}{l}\text { should plan well in order to make sure that IoT is facilitate and it's ready to every single } \\
\text { individual in company/organization..." (Participant 1) }\end{array}$ \\
\hline $\begin{array}{l}\text { Policy and } \\
\text { "...Y Imes. ICT security policy should always support the implementation of IoT to ensure } \\
\text { the effective use of ICT, To force everybody to make it. People in comfort zone always } \\
\text { think that they don't need all this technology because they still can do their job with the } \\
\text { traditional way...." (Participant 4) }\end{array}$ \\
\hline
\end{tabular}

\section{Discussion and Conclusion}

The essential benefaction of the study is the five dimensional factors namely human, technology, secuirty, governance and management and policy and law and their respective elements. These factors were determined based on the data analysed from the preliminary study and interview with the selected key participants. In regard to quantitative result occupying 30 samples of participants, it could be concluded all factors particularly security are significant to be considered in assessing IoT readiness in public agencies. In regard to qualitative result, all five participants have expressed the importance of this readiness factors in IoT implementation. Some improvements bear anticipation in the future. In order to gain further convincing outcomes, some sampling can be further gathered by examining the data with more power statistical techniques. In future, this five factors and their elements can be proposed as theoretical model of IoT readiness in Malaysian public agency and to be tested hypothetically employing larger sample size and power statistics.

\section{References}

1. Asir, T. R. G. 2016. Internet of things and India's readiness, Proceeding International of Applied Engineering Research. January 2015:274-279.

2. Badarudin, U. W., Wan Din, W. I. S., Prasetyo, Y. A., Musa, Z. and Kasim, S. . 2019. Internet of Things: An Implementation and Its Challenges in Malaysia. International Journal on Advanced Science, Engineering and Information Technology, 8(6), p. 2641.

3. Beck, E., Ferguson, M., Walton, K., Maunder, K. and Williams, P. 2018. A framework for eHealth readiness of dietitians', International Journal of Medical Informatics. Elsevier. 115(April):43-52.

4. Burgess, J.,P., Floridi, L., Pols, A., van den Hoven,J. 2018. Towards A Digital Ethics-EDPS Ethics Advisory Group, 2018, https://edps.europa.eu/sites/edp/files/publication/18-0125_eag_report_en.pdf

5. Castelo-Branco, I., Cruz-Jesus, F. and Oliveira, T.2019. Assessing Industry 4.0 readiness in manufacturing: evidence for the European Union. Computers in Industry.107(4): 22-32.

6. Dachyar, M., Zagloel, Y., M., and Saragih, L., R. 2019. Knowledge growth and development: internet of things (IoT) research, 2006-2018. Heliyon. 5(2019):e02264.

7. Eiza, M. H., Randles, M., Johnson, P., Shone, N., Pang, J. and Bhih, A. 2015. Rail Internet of Things: An Architectural Platform and Assured Requirements Model. 15 ${ }^{\text {th }}$ IEEE International Conference on Computer and Information Technology. 25/10:363-370

8. Elazhary, H. 2019. Internet of Things (IoT), mobile cloud, cloudlet, mobile IoT, IoTcloud, fog, mobile edge, and edge emerging computing paradigms: Disambiguation and research directions. Journal of Network and Computer Applications. 128 (15 Feb 2019): 105-140

9. Hussain, A., Manikanthan, S.V., Padmapriya, T., Nagalingam, M. (2020). Genetic algorithm based adaptive offloading for improving IoT device communication efficiency. Wireless Networks, 26 (4), pp. 2329-2338.

10. Hussain, A., Mkpojiogu, E.O.C., Fadzil, N.M., Hassan, N.M. (2017). The UX of amila pregnancy on mobile device. AIP Conference Proceedings, 1891, art. no. 020061, .

11. Katan, R., Mustafa, S. E. and Adnan, H. M. 2018. The Readiness of E-Publishing Among Malaysian Book Publishers. Publishing Research Quarterly. Springer US, 34(3): 362-377.

12. Kauffman, R. J., Ma, D. and Yu, M. 2018. A metrics suite of cloud computing adoption readiness. Electronic Markets. 28(1): 11-37.

13. Lokuge, S., Sedera, D., Grover, V. and Dongming, X. 2018. Organizational readiness for digital innovation: Development and empirical calibration of a construct', Information and Management. November 2016.

14. Lucato, W. C., Pacchini A. P. T., Facchini, F., and Mummolo, G. 2019. Model to evaluate the Industry 4.0 readiness degree in Industrial Companies. IFAC Papers Online 52-13(2019): 18081813

15. MAMPU. 2017. Digital Transformation : Forging Public Sector Digital Future. Public Sector. CIO CONVEX 2017: 1-100.

16. MIMOS. 2015. National Internet of Things (IoT) Strategic Roadmap: A Summary. 
17. Pujar, S.,M., and Satyanarayanab, K., V. 2015. Internet of Things and libraries Shamprasad. Annals of Library and Information Studies. 62(3): 186-190.

18. Radenković, M., Bogdanović, Z., Despotović-Zrakić, M., Labus, A., and Lazarević, S. 2020., Assessing consumer readiness for participation in IoT-based demand response business models. Technological Forecasting and Social Change. Volume 150 (January 2020, 119715)

19. Saarikko, T., Westergren, U. H. and Blomquist, T. 2017. The Internet of Things: Are you ready for what's coming?. Business Horizons. 'Kelley School of Business, Indiana University', 60(5): 667676.

20. Wang, X., Qiu, H. and Xie, F. 2018. A survey on the industrial readiness for internet of things, 2017 IEEE 8th Annual Ubiquitous Computing, Electronics and Mobile Communication Conference, UEMCON 2017, 2018-Janua, pp. 591-596.

21. Xiwei, W., Li, J., Yang, M., Chen, Y. and Xu, X. 2018. An empirical study on the factors influencing mobile library usage in IoT era. Library Hi Tech, 36(4):605-621.

22. Zaidi, A. and Faizal, M. 2017. The IoT readiness of SMEs in Malaysia: are they worthwhile for investigation?. International Conference on International Business, Marketing and Humanities 2017 (ICIBMAH 2017). August: 34-42. 